\title{
ANALISIS KEPUASAN KONSUMEN TERHADAP KUALITAS PELAYANAN TOKO OLEH-OLEH
}

\author{
Hendang Setyo Rukmi ${ }^{1}$, Dwi Novirani ${ }^{2}$, Arinal Hada ${ }^{3}$ \\ ${ }^{1}$ Jurusan Teknik Industri, Institut Teknologi Nasional \\ hendangsetyorukmi@gmail.com \\ ${ }^{2}$ Jurusan Teknik Industri, Institut Teknologi Nasional \\ dwinovirani@gmail.com \\ ${ }^{3}$ Jurusan Teknik Industri, Institut Teknologi Nasional \\ arinalhada@gmail.com
}

\begin{abstract}
ABSTRAK
Munculnya pendatang baru di bisnis penjualan oleh-oleh khas Kota Bandung menyebabkan tingkat persaingan semakin ketat. Adanya penurunan omset penjualan mendorong pihak manajemen toko oleh-oleh khas Kota Bandung "Kabita" ingin memperbaiki kualitas pelayanannya. Perbaikan dilakukan berdasarkan penilaian tingkat kepentingan serta tingkat kepuasan konsumen terhadap kualitas pelayanan yang diberikan Toko "Kabita" dan Toko "Pantai Timur" sebagai pesaing utamanya. Atribut-atribut kualitas pelayanan disusun berdasarkan dimensi tangible, reliability, responsiveness, assurance, dan empathy. Metode yang digunakan adalah Importance Performance Analysis dan Compare Mean Analysis. Pengumpulan data dilakukan dengan menyebarkan kuesioner kepada konsumen yang pernah berbelanja di kedua toko tersebut. Hasil pengolahan data menunjukkan bahwa kepuasan konsumen terhadap kualitas pelayanan Toko "Kabita” secara keseluruhan lebih rendah sekitar 4,6\% dibandingan dengan Toko "Pantai Timur". Atribut-atribut yang harus diperbaiki oleh Toko "Kabita" adalah atribut kejelasan harga barang yang dijual, penampilan karyawan, dan atribut daya tarik sarana promosi karena berada di kuadran 1 dan dinilai memiliki tingkat kepuasan yang lebih rendah dibandingkan dengan Toko "Pantai Timur". Atribut-atribut yang harus dipertahankan oleh Toko "Kabita" adalah atribut daya tarik desain dalam toko atribut kebersihan toko dan sekitarnya, serta atribut kenyamanan toilet karena berada di kuadran 2 dan dinilai lebih memuaskan konsumen dibandingkan Toko "Pantai Timur". Disarankan agar pihak manajemen Toko "Kabita" melakukan perbaikan-perbaikan guna meningkatkan kepuasan konsumennya. Perbaikan yang harus dilakukan adalah menyertakan price tag di setiap produk, penyediaan seragam bagi karyawan baru, dan menggunakan media lain selain media sosial dalam mempromosikan Toko "Kabita".
\end{abstract}

Kata kunci: kualitas pelayanan, Importance Performance Analysis, Compare Mean Analysis.

\section{PENDAHULUAN}

Berdasarkan data dari Biro Pusat Statistik seperti tercantum pada Tabel 1, terlihat bahwa terjadi peningkatan wisatawan yang berkunjung ke Kota Bandung pada Tahun 2010 sampai 2015. Peningkatan wisatawan tersebut berdampak kepada peningkatan omset penjualan oleh-oleh khas Kota Bandung. Prospek usaha yang bagus di bidang penjualan oleh-oleh khas Kota Bandung menyebabkan banyak bermunculan toko oleh-oleh khas Kota Bandung. Akibatnya persaingan usaha diantara toko oleh-oleh khas Kota Bandung semakin meningkat. Oleh karena itu, untuk memenangkan persaingan setiap toko oleh-oleh khas Kota Bandung harus memiliki keunggulan masing-masing.

"Kabita" merupakan salah satu toko yang menjual oleh-oleh khas Kota Bandung yang berlokasi di Jalan Pasteur Bandung. Hingga saat ini toko oleh-oleh khas Kota Bandung yang berada di sekitar Jalan Pasteur berjumlah 15 toko. Sejak banyaknya bermunculan toko oleh-oleh khas Kota Bandung di Jalan Pasteur, omset penjualan Toko "Kabita" menurun. Karena umumnya oleh-oleh khas Kota Bandung yang dijual oleh satu toko dengan toko lainnya relatif sama, upaya untuk memenangkan persaingan adalah memberikan kualitas pelayanan yang unggul. Hal tersebut sesuai dengan pendapat Nhat dan Hau (2007, dalam Sumanti, 2013) yang menyatakan bahwa 
mengkonsentrasikan pada kualitas pelayanan dianggap lebih penting daripada menawarkan produk-produk yang bersifat sama. Selain itu, hasil penelitian Aryani dan Rosinta (2010) di KFC dengan mengambil responden mahasiswa FISIP UI memperlihatkan bahwa terdapat pengaruh yang kuat dan positif antara variabel kualitas layanan terhadap kepuasan konsumennya. Hal serupa juga ditunjukkan oleh hasil penelitian Aryadi (2013) di Giant Supermarket Dinoyo Malang yang memperlihatkan bahwa kualitas pelayanan yang baik kepada konsumen akan meningkatkan kepuasan konsumen itu sendiri. Berdasarkan hal tersebut maka manajemen Toko "Kabita" ingin melakukan perbaikan kualitas pelayanan Toko "Kabita" agar unggul dalam bersaing dan dapat meningkatkan penjualannya.

Tabel 1. Rekapitulasi data kunjungan wisatawan yang datang ke Kota Bandung tahun 2010-2015.

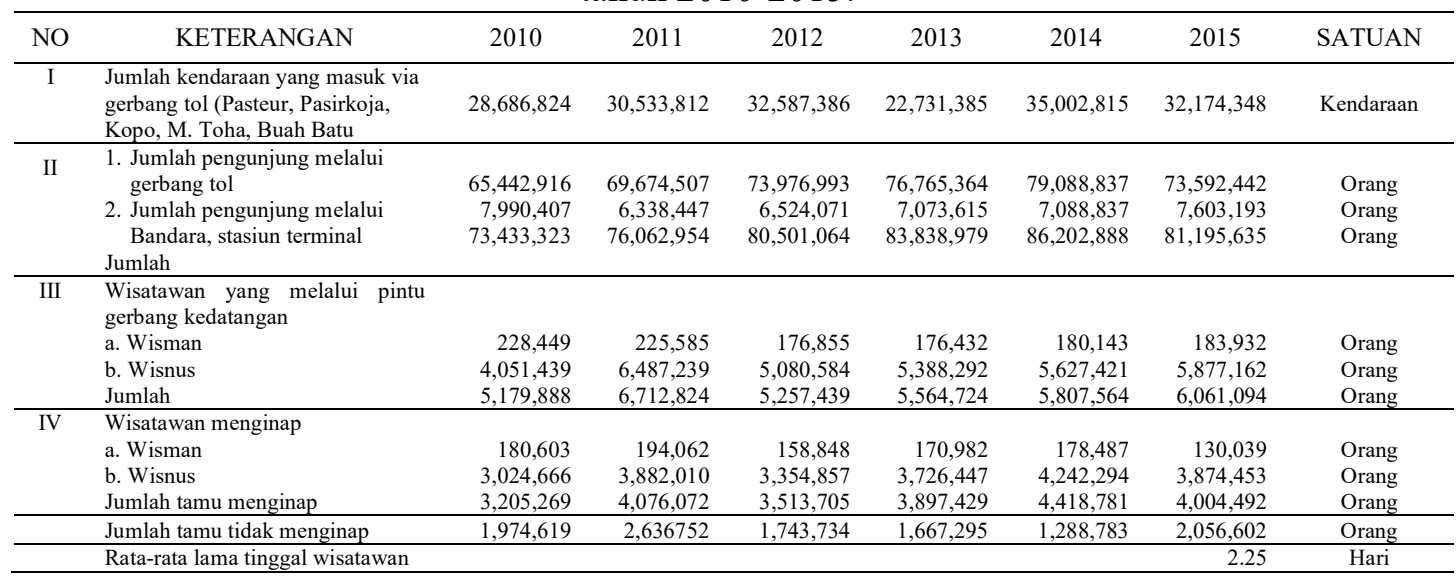

Sumber : (http://data.bandung.go.id/dataset)

Perbaikan kualitas pelayanan toko memerlukan identifikasi atribut kualitas pelayanan yang disebut dimensi penting pada konsumen eceran (Sumanti, 2013). Menurut Parasuraman, et. al (1988, dalam Tjiptono, 2012), kualitas pelayanan dapat diukur berdasarkan lima dimensi, yaitu tangible, reliability, responsiveness, assurance, dan empathy. Pengukuran kualitas pelayanan menggunakan kelima dimensi tersebut telah dilakukan dalam beberapa penelitian. Penelitian Aryani dan Rosinta (2010) menunjukkan bahwa kelima dimensi pembentuk kualitas pelayanan (tangible, reliability, responsiveness, assurance, dan empathy) terbukti berpengaruh secara signifikan terhadap kualitas pelayanan. Penelitian Damora (2013) di Indomaret Prof. Suharso Semarang menunjukkan bahwa dimensi tangible, reliability, responsiveness, assurance, dan empathy berpengaruh secara positif terhadap kepuasan konsumen. Sementara itu, penelitian Ranto (2015) di Toko Modern di Yogyakarta menunjukkan bahwa dimensi reliability, responsiveness, assurance, dan empathy berpengaruh secara signifikan terhadap kepuasan konsumen. Penelitian kepuasan konsumen terhadap kualitas pelayanan di Toko "Kabita" akan menggunakan dimensi tangible, reliability, responsiveness, assurance, dan empathy. Adanya keterbatasan sumber daya yang dimiliki mengharuskan manajemen Toko "Kabita" menentukan skala prioritas perbaikan. Metode yang bisa digunakan untuk menentukan skala prioritas perbaikan kualitas pelayanan Toko "Kabita" adalah Importance Performance Analysis. Menurut Tjiptono (2006), pada Importance-Performance Analysis dilakukan pemetaan atribut kualitas pelayanan ke dalam 4 kuadran. Pembagian kuadran dalam Importance-Performance Analysis adalah Kuadran 1 (Concentrate Here), Kuadran 2 (Keep Up The Good Work), Kuadran 3 (Low Priority), dan Kuadran 4 (Possible Overkill). Atribut-atribut yang diprioritaskan untuk diperbaiki 
adalah atribut yang berada di kuadran 1, yaitu atribut-atribut yang memiliki tingkat kepentingan tinggi tetapi tingkat kepuasannya rendah.

Yola dan Budianto (2013) telah melakukan penelitian mengenai analisis kepuasan konsumen terhadap kualitas pelayanan dan harga produk pada supermarket dengan menggunakan Importance Performance Analysis. Namun penelitian tersebut tidak membandingkan kepuasan konsumen terhadap kualitas pelayanan supermarket yang diteliti dengan pesaing utamanya. Sementara itu, Umiyati dan Suyoto (2014) telah melakukan penelitian mengenai analisis perbandingan kepuasan konsumen atas pelayanan minimarket Indomaret dan Alfamart di wilayah Dukuhwaluh. Namun penelitian tersebut hanya menggunakan uji beda T-Test. Penelitian ini akan menganalisis kepuasan konsumen terhadap kualitas pelayanan toko oleh-oleh khas Kota Bandung "Kabita" dengan pesaing utamanya yaitu Toko "Pantai Timur" menggunakan Importance Performance Analysis serta membandingkan kepuasan konsumen atas pelayanan keduanya dengan menggunakan uji beda T-Test. Toko "Pantai Timur" dianggap pesaing utama karena merupakan toko oleh-oleh khas Kota Bandung yang paling ramai dikunjungi konsumen. Hasil analisis menjadi masukan dalam perbaikan kualitas pelayanan di Toko "Kabita" agar dapat mengungguli pesaing utamanya, yaitu Toko "Pantai Timur".

\section{METODE PENELITIAN}

\section{Penentuan atribut kualitas pelayanan}

Atribut-atribut kualitas pelayanan toko oleh-oleh khas Kota Bandung mengacu kepada konsep kualitas pelayanan (kualitas jasa) dari Parasuraman, et. al (1988, dalam Tjiptono, 2012). Menurut Parasuraman, et. al (1988, dalam Tjiptono, 2012), kualitas jasa dapat dilihat dari 5 dimensi, yaitu: 1) bukti langsung (tangibles), yaitu penampilan fisik fasilitas pelayanan, peralatan/perlengkapan, karyawan, dan materi atau sarana komunikasi.; 2) keandalan (reliability), yaitu kemampuan dalam memberikan pelayanan yang dijanjikan dengan segera, akurat dan memuaskan; 3) daya tanggap (responsiveness), yaitu kesediaan dan kemampuan pemberi jasa untuk membantu dan merespon permintaan konsumen dengan segera dan tanggap; 4) jaminan (assurance), yaitu pengetahuan dan kesopanan karyawan serta kemampuan dalam menumbuhkan rasa percaya (trust) dan keyakinan konsumen (confidence); dan 5) empati, yaitu memahami masalah konsumen dan bertindak demi kepentingan konsumen, serta memberikan perhatian personal kepada para konsumen.

\section{Perancangan alat ukur kualitas pelayanan}

Alat ukur berupa item-item pertanyaan yang diuraikan berdasarkan atribut-atribut kualitas pelayanan toko oleh-oleh khas Kota Bandung. Ada dua alat ukur yang dirancang yaitu alat ukur untuk mengukur tingkat kepentingan dan alat ukur untuk mengukur tingkat kepuasan. Skala yang digunakan untuk mengukur tingkat kepentingan adalah Sangat Penting (Nilai 4), Penting (Nilai 3), Tidak Penting (Nilai 2), dan Sangat Tidak Penting (Nilai 1). Skala yang digunakan untuk mengukur tingkat kepuasan adalah Sangat Puas (Nilai 4), Puas (Nilai 3), Tidak Puas (Nilai 2), dan Sangat Tidak Puas (Nilai 1).

\section{Pengujian alat ukur}

Untuk mengetahui kelayakannya, alat ukur diuji validitas dan reliabilitasnya. Uji validitas bertujuan untuk mengetahui apakah alat ukur benar-benar mengukur apa yang akan diukur, sedangkan uji reliabilitas bertujuan untuk mengetahui apakah alat ukur konsisten jika digunakan pada waktu pengukuran yang berbeda selama objek yang diukur tidak berubah. Uji validitas 
menggunakan Korelasi Product Moment. Alat ukur dinyatakan valid jika item-item pernyataannya memiliki $r_{\text {hitung }}>\mathrm{r}_{\text {tabel }}$ (Singarimbun, 2010). Uji reliabilitas menggunakan metode Alpha Cronbach. Jika koefisien alpha cronbach $(\propto) \geq 0,6$ maka alat ukur dinyatakan cukup reliabel (Azwar, 2013). Pengujian alat ukur dilakukan dengan bantuan software SPSS.

\section{Importance performance analysis}

Pada Importance-Performance Analysis, dilakukan pemetaan atribut kualitas pelayanan ke dalam 4 kuadran. Pembagian kuadran dalam Importance-Performance Analysis adalah Kuadran 1 (Concentrate Here), Kuadran 2 (Keep Up The Good Work), Kuadran 3 (Low Priority), dan Kuadran 4 (Possible Overkill) (Tjiptono, 2006). Langkah-langkah Importance-Performance Analysis adalah:

1. Hitung rata-rata Nilai Indeks Kepentingan (NIKi) dan rata-rata Nilai Indeks Kepuasan (NIKp) dari seluruh responden untuk setiap atribut.

2. Hitung nilai rata-rata dari NIKi atau $\overline{N I K i}$

3. Hitung nilai rata-rata dari NIKp atau $\overline{N I K p}$

4. Plot nilai $\overline{N I K i}$ dan nilai $\overline{N I K p}$ ke Diagram Kartesius. Nilai $\overline{N I K i}$ merupakan nilai y sedangkan nilai $\overline{N I K p}$ merupakan nilai $\mathrm{x}$.

5. Tarik garis sepanjang nilai $\overline{N I K i}$ dan nilai $\overline{N I K p}$. Garis tersebut merupakan batas kuadran seperti terlihat pada Gambar 1.

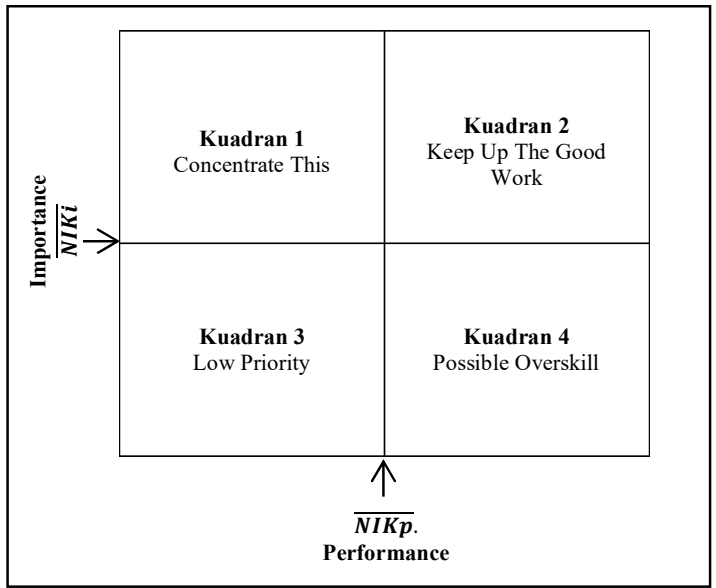

Gambar 1. Diagram Importance Performance Matrix

Sumber (Tjiptono, 2006)

\section{Compare mean analysis}

Compare Mean Analysis atau analisis perbandingan rata-rata adalah bentuk analisis variabel (data) untuk mengetahui perbedaan diantara dua kelompok data (variabel) atau lebih (Misbahuddin, 2013). Langkah-angkah Compare Mean Analysis adalah :

1. Tentukan formulasi hipotesisnya

$\mathrm{H}_{\mathrm{o}}: \mathrm{X}=\mu \mathrm{o}$

$\mathrm{H}_{1}: \mathrm{X} \neq \mu \mathrm{o}$

2. Hitung rata-rata sampel

3. Hitung nilai standar deviasi sampel

4. Hitung nilai $\mathrm{t}$ menggunakan paired-sample $t$ test (pada penelitian ini uji $\mathrm{t}$ sampel berpasangan) 
5. Tentukan nilai $\mathrm{t}_{\text {tabel }}$ (untuk nilai $\alpha$ dan derajat kebebasan (degree of freedom, $\left.d f\right)=\mathrm{n}-1$ ).

6. Tarik kesimpulan

Bandingkan nilai $t_{\text {hitung }}$ dengan $t_{\text {tabel }}$. Jika $t_{\text {hitung }}>t_{\text {tabel }}$, maka Ho ditolak, artinya nilai rata-rata yang diharapkan berbeda dengan nilai rata-rata pengukuran sampel. Jika $t_{\text {hitung }}<\mathrm{t}$ tabel maka Ho diterima atau dapat dikatakan rata-rata yang dibandingkan adalah sama.

\section{HASIL DAN PEMBAHASAN}

Pengumpulan data dilakukan dengan menggunakan kuesioner. Responden penelitian ini adalah konsumen yang pernah berbelanja di Toko "Kabita" dan Toko "Pantai Timur" sebanyak 93 orang. Kuesioner berupa item-item pertanyaan yang disusun mengacu pada atribut kualitas pelayanan jasa Parasuraman, et. al (1988, dalam Tjiptono, 2012). Terdiri dari dua jenis kuesioner yaitu kuesioner untuk mengukur tingkat kepentingan dan kuesioner untuk mengukur tingkat kepuasan. Contoh pertanyaan dalam kuesioner dapat dilihat pada Tabel 2. Data mentah dari kuesioner diolah dengan menggunakan Importance Performance Analysis dan Compare Mean Analysis. Tabel 3 menunjukkan Nilai Indeks Kepentingan (NIKi). Tabel 4 menunjukkan Nilai Indeks Kepuasan (NIKp) untuk Toko "Kabita" dan Toko "Pantai Timur". Gambar 2 menunjukkan posisi atribut kualitas pelayanan "Toko Kabita" dan "Toko Pantai Timur" pada Importance Performance Matrix. Tabel 5 memperlihatkan atribut kualitas pelayanan di setiap kuadran untuk Toko "Kabita" dan untuk Toko "Pantai Timur".

Tabel 2. Contoh pertanyaan dalam kuesioner penelitian

\begin{tabular}{|c|c|c|c|c|}
\hline $\begin{array}{c}\text { Dimensi } \\
\text { kualitas } \\
\text { pelayanan }\end{array}$ & $\begin{array}{c}\text { Atribut } \\
\text { kualitas } \\
\text { pelayanan }\end{array}$ & $\begin{array}{l}\text { Item pertanyaan tingkat } \\
\text { kepentingan konsumen }\end{array}$ & $\begin{array}{l}\text { Item pertanyaan tingkat } \\
\text { kepuasan konsumen pada } \\
\text { Toko "Kabita" }\end{array}$ & $\begin{array}{l}\text { Item pertanyaan tingkat } \\
\text { kepuasan konsumen pada } \\
\text { Toko "Pantai Timur" }\end{array}$ \\
\hline \multirow[t]{2}{*}{ Responsiveness } & \multirow{2}{*}{$\begin{array}{c}\text { Kecepatan } \\
\text { karyawan } \\
\text { dalam } \\
\text { melayani } \\
\text { konsumen } \\
\text { (X16) }\end{array}$} & $\begin{array}{l}\text { Seberapa pentingkah } \\
\text { kecepatan karyawan dalam } \\
\text { melayani konsumen di } \\
\text { sebuah toko oleh-oleh? }\end{array}$ & $\begin{array}{l}\text { Seberapa puaskah Anda } \\
\text { dengan kecepatan } \\
\text { karyawan Toko "Kabita" } \\
\text { dalam melayani } \\
\text { konsumen? }\end{array}$ & $\begin{array}{c}\text { Seberapa puaskah Anda } \\
\text { dengan kecepatan } \\
\text { karyawan Toko "Pantai } \\
\text { Timur" dalam melayani } \\
\text { konsumen? } \\
\end{array}$ \\
\hline & & $\begin{array}{l}\text { Sangat } \\
\text { Tidak Tidak } \\
\text { Penting }\end{array}$ & $\begin{array}{ccc}\text { Sangat } & \text { Tidak } & \\
\text { Tidak } & \text { Sangat } \\
\text { Puas } & \text { Puas } & \text { Puas } \\
\end{array}$ & $\begin{array}{cccc}\begin{array}{c}\text { Sangat } \\
\text { Tidak }\end{array} & \text { Tidak } & & \text { Sangat } \\
\text { Puas } & \text { Puas } & \text { Puas } & \text { Puas } \\
\end{array}$ \\
\hline
\end{tabular}

Tabel 3. Nilai Indeks Kepentingan (NIKi).

\begin{tabular}{ccccccc}
\hline $\begin{array}{c}\text { Atribut } \\
(\mathrm{Y})\end{array}$ & \multicolumn{5}{c}{ Skala $(\mathrm{Nj})$} & \multicolumn{1}{c}{ Total } \\
\cline { 2 - 5 } & 1 & 2 & 3 & 4 & \multirow{2}{*}{ Responden } & \\
\hline 1 & 0 & 11 & 44 & 38 & 93 & 3.290 \\
\hline 2 & 0 & 15 & 33 & 45 & 93 & 3.323 \\
\hline 3 & 0 & 11 & 39 & 43 & 93 & 3.344 \\
\hline 4 & 0 & 8 & 45 & 40 & 93 & 3.344 \\
\hline 5 & 0 & 10 & 40 & 43 & 93 & 3.355 \\
\hline 6 & 0 & 11 & 47 & 35 & 93 & 3.258 \\
\hline 7 & 0 & 13 & 41 & 39 & 93 & 3.280 \\
\hline 8 & 0 & 6 & 43 & 45 & 93 & 3.419 \\
\hline 9 & 0 & 11 & 39 & 43 & 93 & 3.344 \\
\hline 10 & 0 & 11 & 40 & 42 & 93 & 3.333 \\
\hline 11 & 0 & 8 & 44 & 41 & 93 & 3.355 \\
\hline 12 & 0 & 12 & 36 & 45 & 93 & 3.355 \\
\hline 13 & 0 & 9 & 46 & 38 & 93 & 3.312 \\
\hline 14 & 0 & 8 & 40 & 45 & 93 & 3.398 \\
\hline
\end{tabular}


Tabel 3. Nilai Indeks Kepentingan (NIKi) (lanjutan)

\begin{tabular}{|c|c|c|c|c|c|c|}
\hline \multirow{2}{*}{$\begin{array}{l}\text { Atribut } \\
\text { (Y) }\end{array}$} & \multicolumn{4}{|c|}{ Skala $(\mathrm{Nj})$} & \multirow{2}{*}{$\begin{array}{c}\text { Total } \\
\text { Responden }\end{array}$} & \multirow{2}{*}{ NIKi } \\
\hline & 1 & 2 & 3 & 4 & & \\
\hline 15 & 0 & 11 & 43 & 39 & 93 & 3.301 \\
\hline 16 & 0 & 11 & 47 & 35 & 93 & 3.258 \\
\hline 17 & 0 & 10 & 45 & 38 & 93 & 3.301 \\
\hline 18 & 0 & 8 & 40 & 45 & 93 & 3.398 \\
\hline 19 & 0 & 8 & 39 & 46 & 93 & 3.409 \\
\hline 20 & 0 & 11 & 37 & 45 & 93 & 3.366 \\
\hline 21 & 0 & 11 & 38 & 44 & 93 & 3.355 \\
\hline 22 & 0 & 11 & 43 & 39 & 93 & 3.301 \\
\hline 23 & 0 & 14 & 35 & 43 & 93 & 3.315 \\
\hline \multicolumn{6}{|c|}{ TOTAL NIKi } & 76.714 \\
\hline & & & & & & 3.335 \\
\hline
\end{tabular}

Berikut adalah contoh perhitungan NIKi untuk atribut 1 dan contoh perhitungan $\overline{N I K i}$ : $\mathrm{NIK}_{\mathrm{i}}$ Atribut $1=\left(\left(\mathrm{Nj} . \mathrm{X}_{1}\right)\right) /($ Total Responden $)=((1 \mathrm{x} 0)+(2 \times 11)+(3 \mathrm{x} 44)+(4 \times 38)) / 93=3.290$ $\overline{N I K i}=($ Total NIKi $) / \mathrm{Y}=76.714 / 23=3.335$

Tabel 4. Nilai Indeks Kepuasan (NIKp) untuk Toko "Kabita" dan Toko "Pantai Timur"

\begin{tabular}{|c|c|c|c|c|c|c|c|c|c|c|c|}
\hline \multirow{3}{*}{$\begin{array}{l}\text { Atribut } \\
\text { (Y) }\end{array}$} & \multirow{3}{*}{$\begin{array}{c}\text { Jumlah } \\
\text { Responden }\end{array}$} & \multicolumn{5}{|c|}{ Toko "Kabita" } & \multicolumn{5}{|c|}{ Toko "Pantai Timur" } \\
\hline & & \multicolumn{4}{|c|}{ Skala $(\mathrm{Nj})$} & \multirow{2}{*}{ NIKp } & \multicolumn{4}{|c|}{ Skala $(\mathrm{Nj})$} & \multirow{2}{*}{ NIKp } \\
\hline & & 1 & 2 & 3 & 4 & & 1 & 2 & 3 & 4 & \\
\hline 1 & 93 & 2 & 0 & 34 & 57 & 3.570 & 6 & 10 & 37 & 40 & 3.194 \\
\hline 2 & 93 & 1 & 0 & 39 & 53 & 3.548 & 0 & 0 & 31 & 62 & 3.667 \\
\hline 3 & 93 & 0 & 3 & 28 & 62 & 3.634 & 2 & 1 & 43 & 47 & 3.452 \\
\hline 4 & 93 & 1 & 0 & 36 & 56 & 3.581 & 3 & 12 & 43 & 35 & 3.183 \\
\hline 5 & 93 & 1 & 0 & 47 & 45 & 3.462 & 19 & 16 & 31 & 27 & 2.710 \\
\hline 6 & 93 & 1 & 0 & 51 & 41 & 3.419 & 27 & 21 & 25 & 20 & 2.409 \\
\hline 7 & 93 & 0 & 0 & 56 & 37 & 3.398 & 0 & 1 & 34 & 58 & 3.612 \\
\hline 8 & 93 & 1 & 0 & 44 & 48 & 3.495 & 0 & 2 & 38 & 53 & 3.548 \\
\hline 9 & 93 & 27 & 21 & 20 & 25 & 2.462 & 1 & 0 & 36 & 56 & 3.581 \\
\hline 10 & 93 & 18 & 21 & 30 & 24 & 2.645 & 1 & 0 & 36 & 56 & 3.581 \\
\hline 11 & 93 & 26 & 34 & 15 & 18 & 2.269 & 1 & 0 & 49 & 43 & 3.441 \\
\hline 12 & 93 & 23 & 24 & 19 & 27 & 2.538 & 1 & 1 & 44 & 47 & 3.473 \\
\hline 13 & 93 & 0 & 1 & 46 & 46 & 3.484 & 0 & 2 & 43 & 48 & 3.495 \\
\hline 14 & 93 & 1 & 0 & 49 & 43 & 3.441 & 0 & 2 & 36 & 55 & 3.570 \\
\hline 15 & 93 & 0 & 0 & 40 & 53 & 3.570 & 0 & 1 & 43 & 49 & 3.516 \\
\hline 16 & 93 & 25 & 22 & 25 & 21 & 2.452 & 0 & 1 & 43 & 49 & 3.516 \\
\hline 17 & 93 & 24 & 26 & 24 & 19 & 2.409 & 0 & 1 & 48 & 44 & 3.462 \\
\hline 18 & 93 & 0 & 1 & 48 & 44 & 3.462 & 0 & 1 & 46 & 46 & 3.484 \\
\hline 19 & 93 & 0 & 5 & 37 & 51 & 3.495 & 0 & 1 & 39 & 53 & 3.559 \\
\hline 20 & 93 & 2 & 3 & 35 & 53 & 3.495 & 1 & 0 & 40 & 52 & 3.538 \\
\hline 21 & 93 & 1 & 4 & 42 & 46 & 3.430 & 1 & 0 & 43 & 49 & 3.505 \\
\hline 22 & 93 & 27 & 16 & 23 & 27 & 2.538 & 1 & 0 & 34 & 58 & 3.602 \\
\hline \multirow[t]{3}{*}{23} & 93 & 1 & 3 & 34 & 55 & 3.538 & 1 & 0 & 30 & 62 & 3.645 \\
\hline & & & & \multicolumn{2}{|c|}{ Total NIKp } & 73,335 & & & \multicolumn{2}{|c|}{ Total NIKp } & 78.742 \\
\hline & & & & & $\overline{\mathrm{NIKp}}$ & 3.188 & & & & $\overline{\overline{N I K p}}$ & 3,424 \\
\hline
\end{tabular}

Berikut adalah contoh perhitungan NIKp Toko "Kabita" untuk atribut 1 dan $\overline{N I K p}$ :

$\mathrm{NIK}_{1}$ Atribut $1=((\mathrm{Nj} . \mathrm{Xl})) /($ Total Responden $)=((1 \times 2)+(2 \times 0)+(3 \times 34)+(4 \times 57)) / 93=3.570$

$\overline{N I K p}=($ Total NIKi $) / Y=73.335 / 23=3.188$ 
Dari Gambar 2 dan Tabel 5 terlihat bahwa atribut kualitas pelayanan yang harus diperbaiki oleh Toko "Kabita" adalah atribut kebersihan dan kerapian penampilan karyawan (atribut 9), daya tarik sarana promosi (atribut 11), dan kejelasan barang yang dijual (atribut 12), sedangkan atribut kualitas pelayananyang harus diperbaiki oleh Toko "Pantai Timur" adalah kebersihan toko dan sekitarnya (atribut 4) dan kenyamanan toilet (atribut 5). Atribut kualitas pelayanan tersebut berada di kuadran 1 (Concentrate Here), yaitu wilayah yang memuat faktor-faktor yang dianggap penting oleh pelanggan, tetapi pada kenyataannya faktor-faktor ini belum sesuai dengan harapan pelanggan (tingkat kepuasan yang diperoleh masih rendah).

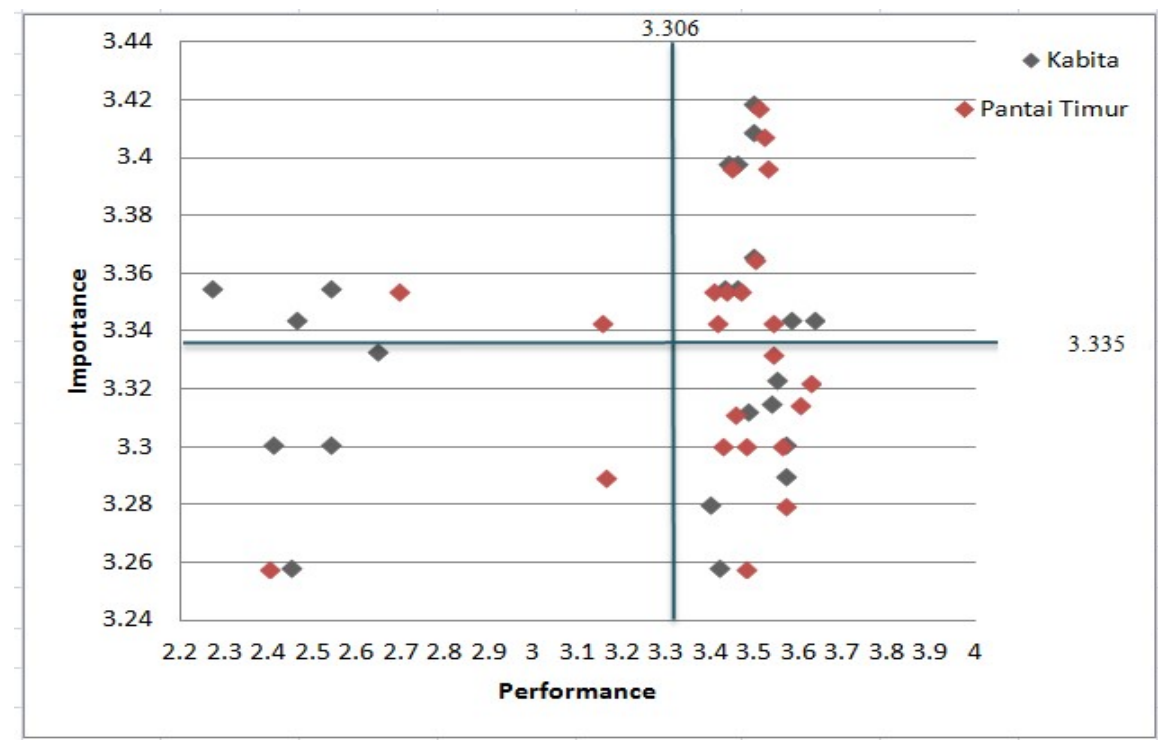

Gambar 2. Importance Performance Matrix untuk Toko "Kabita” dan Toko "Pantai Timur"

Atribut-atribut daya tarik desain dalam toko (atribut 3), kebersihan toko dan sekitarnya (atribut 4), kenyamanan toilet (atribut 5), kondisi peralatan yang digunakan (atribut 8), kehalalan makanan yang dijual (atribut 14), keamanan tempat parker (atribut 18), keamanan transaksi dengan menggunakan transaksi elektronik (atribut 19), kemudahan menyampaikan kritik/saran (atribut 20), serta follow up kritik dan saran (atribut 21) merupakan atribut-atribut kualitas pelayanan yang harus dipertahankan oleh Toko "Kabita". Kondisi tersebut hampir sama dengan di Toko "Pantai Timur". Atribut kualitas pelayanan tersebut berada di kuadran 2 (Keep Up The Good Work), yaitu wilayah yang memuat atribut-atribut yang dianggap penting oleh pelanggan, dan atribut-atribut yang dianggap pelanggan sudah sesuai dengan yang dirasakannya sehingga tingkat kepuasannya relatif lebih tinggi. Atribut-atribut yang masuk dalam kuadran ini harus tetap dipertahankan karena semua atribut ini menjadikan produk atau jasa unggul di mata pelanggan.

Tabel 6 dan Tabel 7 menunjukkan hasil pengolahan data dengan menggunakan Analysis Compare Mean. Dari Tabel 6 terlihat bahwa ada perbedaan tingkat kepuasan konsumen secara keseluruhan untuk kualitas pelayanan di Toko "Kabita" dan di Toko "Pantai Timur" karena nilai $t_{\text {hitung }}$ lebih besar daripada nilai $t_{\text {tabel }}$. Berdasarkan hasil perhitungan Performance Importance Analysis diketahui bahwa nilai rata-rata skor kepuasan ( $\overline{N I K i})$ Toko "Kabita" sebesar 3,188, lebih rendah dibandingkan nilai rata-rata skor kepuasan $(\overline{N I K i})$ Toko "Pantai Timur" yang memiliki nilai 3,424. Jika mengacu kepada indeks tingkat kepuasan maksimal (nilainya 4), maka 
tingkat kepuasan Toko "Kabita" adalah sebesar 79,7\% sedangkan tingkat kepuasan Toko "Pantai Timur" sebesar 83,4\%. Selisih tingkat kepuasan antara Toko "Kabita" dengan Toko "Pantai Timur" adalah sebesar 4,6\%.

Tabel 5. Posisi Atribut Kualitas Pelayanan Toko "Kabita" dan Toko "Pantai Timur"

\begin{tabular}{|c|c|c|c|c|}
\hline Kuadran & $\begin{array}{l}\text { Aribut untuk } \\
\text { Toko Kabita }\end{array}$ & $\begin{array}{c}\text { Atribut untuk } \\
\text { Toko Pantai } \\
\text { Timur }\end{array}$ & & Keterangan atribut \\
\hline \multirow{6}{*}{1} & \multirow{6}{*}{$9,11,12$} & \multirow{6}{*}{4,5} & 1 & Kenyamanan lahan parkir (mudah, ada petugas). \\
\hline & & & 2 & Daya tarik desain luar toko (neon box, cat tembok). \\
\hline & & & 3 & Daya tarik desain dalam toko (cat tembok, penataan barang). \\
\hline & & & 4 & Kebersihan toko dan sekitarnya. \\
\hline & & & 5 & $\begin{array}{l}\text { Kenyamanan toilet (air bersih, perlengkapan tersedia, dan } \\
\text { kebersihan toilet). }\end{array}$ \\
\hline & & & 6 & $\begin{array}{l}\text { Ketersediaan mushola yang nyaman (kebersihan, kelengkapan } \\
\text { alat sholat). }\end{array}$ \\
\hline \multirow{6}{*}{2} & \multirow{6}{*}{$\begin{array}{c}3,4,5,8, \\
14,18,19, \\
20,21\end{array}$} & \multirow{6}{*}{$\begin{array}{c}3,8,9,11 \\
12,14,18 \\
19,20,21\end{array}$} & 7 & $\begin{array}{l}\text { Kelengkapan peralatan yang digunakan (mesin kasir, } \\
\text { timbangan, lemari pendingin, rak penyimpanan makanan). }\end{array}$ \\
\hline & & & 8 & Kondisi peralatan yang digunakan. \\
\hline & & & 9 & Kebersihan dan kerapian penampilan karyawan. \\
\hline & & & 10 & Daya tarik penampilan karyawan (seragam). \\
\hline & & & 11 & Daya tarik sarana promosi (brosur, pamflet). \\
\hline & & & 12 & Kejelasan harga barang yang dijual (price tag). \\
\hline \multirow{6}{*}{3} & \multirow{6}{*}{$\begin{array}{l}10,16,17, \\
22\end{array}$} & \multirow{6}{*}{1,6} & 13 & Kualitas makanan yang dijual (rasa, kebersihan, kadaluarsa). \\
\hline & & & 14 & Kehalalan makanan yang dijual. \\
\hline & & & 15 & Kesesuaian harga yang dibayar dengan jumlah yang dibeli. \\
\hline & & & 16 & Kecepatan karyawan dalam melayani konsumen. \\
\hline & & & 17 & Keramahan dan kesopanan karyawan. \\
\hline & & & 18 & Keamanan tempat parker. \\
\hline \multirow{5}{*}{4} & \multirow{5}{*}{$\begin{array}{l}1,2,6,7 \\
13,15,23\end{array}$} & \multirow{5}{*}{$\begin{array}{c}2,7,10,13 \\
15,16,17 \\
22,23\end{array}$} & 19 & $\begin{array}{l}\text { Keamanan transaksi dengan menggunakan pembayaran } \\
\text { elektronik (debit, kartu kredit). }\end{array}$ \\
\hline & & & 20 & $\begin{array}{l}\text { Kemudahan akses untuk menyampaikan kritik dan saran serta } \\
\text { keluhan pelanggan. }\end{array}$ \\
\hline & & & 21 & Follow up kritik dan saran. \\
\hline & & & 22 & Lamanya waktu pelayanan. \\
\hline & & & 23 & Lokasi toko strategis. \\
\hline
\end{tabular}

Tabel 6. Hasil Uji Perbandingan Tingkat Kepuasan Konsumen Secara Keseluruhan Terhadap Kualitas Pelayanan Toko "Kabita" dan Toko "Pantai Timur"

\begin{tabular}{cccccccc}
\hline \multirow{2}{*}{ Perbandingan } & \multirow{2}{*}{ thitung } & \multirow{2}{*}{ t tabel } & \multirow{2}{*}{ Sig } & \multicolumn{2}{c}{ Toko Kabita } & \multicolumn{2}{c}{ Toko Pantai Timur } \\
\cline { 5 - 7 } & & & & Mean & Standar Deviasi & Mean & Standar Deviasi \\
\hline $\begin{array}{c}\text { Tingkat } \\
\text { Kepuasan }\end{array}$ & 6.115 & 1.973 & 0.000 & 73.33 & 6.29 & 78.74 & 5.76 \\
\hline
\end{tabular}

Pada Tabel 7 terlihat bahwa atribut yang dibandingkan tingkat kepuasan konsumennya adalah atribut kualitas pelayanan yang berada di kuadran 1 dan kuadran 2. Dari Tabel 5 terlihat bahwa atribut-atribut kualitas pelayanan yang berada di kuadran 1 dan 2 relatif sama antara Toko "Kabita" dan Toko "Pantai Timur". Dari Tabel 7 terlihat bahwa nilai thitung untuk atribut daya tarik desain dalam toko (atribut 3), kebersihan toko dan sekitarnya (atribut 4), kenyamanan toilet (atribut 5), penampilan karyawan (atribut 9), daya tarik sarana promosi (atribut 11), kejelasan harga barang yang dijual (atribut 12) lebih besar daripada nilai $t_{\text {tabel }}$ untuk taraf signifikansi $<$ 0.05. Dengan demikian dapat dinyatakan bahwa untuk seluruh atribut tersebut terjadi penolakan Ho. Artinya terdapat perbedaan kepuasan konsumen terhadap kualitas pelayanan yang signifikan 
antara Toko "Kabita" dan Toko "Pantai Timur" untuk atribut-atribut tersebut. Dengan demikian atribut kejelasan harga barang yang dijual (atribut 12), penampilan karyawan (atribut 9), dan atribut daya tarik sarana promosi (atribut 11) harus diperbaiki oleh Toko "Kabita". Atribut daya tarik desain dalam toko (atribut 3), atribut kebersihan toko dan sekitarnya (atribut 4), dan atribut kenyamanan toilet (atribut 5) harus dipertahankan oleh Toko "Kabita".

Tabel 7. Hasil Uji Perbandingan Tingkat Kepuasan Konsumen untuk Atribut Kualitas Pelayanan Kuadran di 1 dan 2 antara Toko "Kabita" dan Toko "Pantai Timur"

\begin{tabular}{|c|c|c|c|c|c|c|c|c|}
\hline \multirow{2}{*}{ No } & \multirow{2}{*}{ Atribut } & \multirow{2}{*}{$\mathrm{t}$ hitung } & \multirow{2}{*}{$\mathrm{t}$ tabel } & \multirow{2}{*}{ Sig } & \multicolumn{2}{|c|}{ Toko Kabita } & \multicolumn{2}{|c|}{ Toko Pantai Timur } \\
\hline & & & & & Mean & Standar Deviasi & Mean & Standar Deviasi \\
\hline 1 & Atribut 3 & 2,014 & 1.973 & 0.037 & 3.634 & 0.547 & 3.452 & 0.634 \\
\hline 2 & Atribut 4 & 2.298 & 1.973 & 0.023 & 3.581 & 0.558 & 3.183 & 0.590 \\
\hline 3 & Atribut 5 & 5.878 & 1.973 & 0.000 & 3.462 & 0.563 & 2.710 & 1.099 \\
\hline 4 & Atribut 8 & 0.663 & 1.973 & 0.508 & 3.495 & 0.564 & 3.548 & 0.542 \\
\hline 5 & Atribut 9 & 8.288 & 1.973 & 0.000 & 2.462 & 1.175 & 3.581 & 0.558 \\
\hline 6 & Atribut 11 & 9.324 & 1.973 & 0.000 & 2.269 & 1.075 & 3.441 & 0.561 \\
\hline 7 & Atribut 12 & 6.966 & 1.973 & 0.000 & 2.538 & 1.157 & 3.473 & 0.582 \\
\hline 8 & Atribut 14 & 1.599 & 1.973 & 0.112 & 3.441 & 0.561 & 3.570 & 0.540 \\
\hline 9 & Atribut 18 & 0.280 & 1.973 & 0.780 & 3.462 & 0.523 & 3.484 & 0.524 \\
\hline 10 & Atribut 19 & 0.782 & 1.973 & 0.435 & 3.495 & 0.601 & 3.559 & 0.521 \\
\hline 11 & Atribut 20 & 0.474 & 1.973 & 0.636 & 3.495 & 0.670 & 3.538 & 0.563 \\
\hline 12 & Atribut 21 & 0.857 & 1.973 & 0.393 & 3.430 & 0.632 & 3.505 & 0.564 \\
\hline
\end{tabular}

Atribut kejelasan harga barang di Toko "Kabita" dinilai kurang memuaskan konsumen karena berdasarkan kondisi saat ini barang yang dijual di Toko "Kabita" sebagian besar tidak memakai price tag. Hal tersebut dilakukan untuk mengantisipasi adanya perubahan kenaikan harga agar tidak perlu membuka dan menempel daftar harga di produk yang dijual. Tak jarang hal tersebut membuat konsumen bingung dan harus bertanya kepada karyawan tentang harga barang yang dijual. Dibandingkan dengan Toko "Pantai Timur", hampir semua produk memiliki daftar harga. Perbaikan yang diusulkan adalah dengan memberi price tagdi seluruh produk yang dijual.

Atribut penampilan karyawan Toko "Kabita" dinilai kurang memuaskan konsumen karena tidak semua karyawan menggunakan seragam, terutama karyawan baru. Karena tingkat keluar masuk karyawan cukup sering, karyawan baru seringkali harus menunggu untuk dibuatkan seragam. Pakaian yang digunakan cukup bersih namun seringkali terlihat kurang rapi. Dibandingkan dengan Toko "Pantai Timur", semua karyawannya menggunakan seragam dan terlihat rapi. Oleh karena itu manajemen Toko "Kabita" perlu menambah stok baju seragam untuk karyawan baru.

Atribut daya tarik sarana promosi di Toko "Kabita" dinilai kurang memuaskan konsumen karena untuk kondisi saat ini Toko "Kabita" hanya mengandalkan promosi lewat media sosial sehingga konsumen yang tidak menggunakan media sosial tidak akan mengetahui keberadaan Toko "Kabita". Sebaiknya Toko "Kabita" dipromosikan juga melalui pamflet ataupun brosur, pameran-pameran makanan (Bandung Culinary Night, Food Bandung Expo, Bandung Food Ingredients) seperti yang dilakukan Toko "Pantai Timur".

\section{KESIMPULAN DAN SARAN}

\section{Kesimpulan}

Pada penelitian ini dapat disimpulkan bahwa ada perbedaan kepuasan konsumen terhadap kualitas pelayanan Toko "Kabita" dengan Toko "Pantai Timur" dimana nilai kepuasan total 
Toko Kabita lebih rendah (4,6 \%) dibandingkan Toko "Pantai Timur". Selain itu, perbedaan kepuasan konsumen juga terjadi untuk atribut daya tarik desain dalam toko (atribut 3), kebersihan toko dan sekitarnya (atribut 4), kenyamanan toilet (atribut 5), penampilan karyawan (atribut 9), daya tarik sarana promosi (atribut 11), dan kejelasan barang yang dijual (atribut 12).

Atribut-atribut yang harus diperbaiki oleh pihak manajemen Toko "Kabita" adalah atribut kejelasan harga barang yang dijual (atribut 12), penampilan karyawan (atribut 9), dan atribut daya tarik sarana promosi (atribut 11) dimana kondisi ketiga atribut tersebut kurang baik bila dibandingkan dengan Toko "Pantai Timur. Atribut-atribut yang harus dipertahankan oleh pihak manajemen Toko "Kabita" adalah atribut daya tarik desain dalam toko (atribut 3), atribut kebersihan toko dan sekitarnya (atribut 4), dan atribut kenyamanan toilet (atribut 5) dimana kondisi ketiga atribut tersebut lebih baik dibandingkan Toko "Pantai Timur".

\section{Saran}

Disarankan agar pihak manajemen manajemen Toko "Kabita" melakukan perbaikan-perbaikan guna meningkatkan kepuasan konsumennya. Perbaikan yang harus dilakukan adalah menyertakan price tag di setiap produk, penyediaan seragam bagi karyawan baru, dan menggunakan media lain selain media sosial dalam mempromosikan Toko "Kabita".

\section{REFERENSI}

Azwar, S. (2013). Metode penelitian. Pustaka Pelajar, Yogyakarta.

Aryadi, DF. (2013). Pengaruh kualitas pelayanan terhadap kepuasan pelanggan (studi pada Giant Supermarket Dinoyo Malang). Jurnal Universitas Brawijaya, 1(1), 1- 23.

Aryani D. dan Rosinta, F. (2010). Pengaruh kualitas layanan terhadap kepuasan pelanggan dalam membentuk loyalitas pelanggan. Jurnal Ilmu Administrasi dan Organisasi, 17(2), 114-126.

Damora, D. (2013). Analisis pengaruh kualitas pelayanan terhadap kepuasan konsumen pada minimarket Indomaret (studi kasus pada Indomaret Prof. Suharso Semarang). Dinamika Manajemen, 2(1), 97-112.

Misbahuddin dan Iqbal, H. (2013). Analisis data penelitian dengan statistik, edisi ke-2. PT Bumi Aksara, Jakarta.

Ranto, DWP. (2015). Pengaruh kualitas pelayanan terhadap kepuasan pelanggan berbelanja pada toko Modern di Yogyakarta. Jurnal Bisnis Teori dan Implementasi, 6(1), 15-32.

Singarimbun, M. dan Effendi, S. (2010). Metode penelitian survai. Pustaka LP3ES, Jakarta.

Sumanti, P. (2013). Pengaruh kualitas pelayanan terhadap kepuasan pelanggan pada toko serba ada (studi kasus Carrefour Jakarta Selatan). Tesis-Program Magister Manajemen, Universitas Terbuka, Jakarta.

Tjiptono, F. (2006). Manajemen Jasa. Andi Offset, Yogyakarta.

Tjiptono, F. (2012). Service management mewujudkan layanan prima. Andi Offset, Yogyakarta.

Umyati dan Suyoto. (2014). Analisis perbandingan kepuasan konsumen atas pelayanan minimarket Indomaret dan Alfamart di wilayah Dukuhwaluh. Media Ekonomi, 14 (2), 6476.

Yola M. dan Budianto D. (2013). Analisis kepuasan konsumen terhadap kualitas pelayanan dan harga produk pada supermarket dengan menggunakan metode Importance Performance Analysis (IPA). Jurnal Optimasi Sistem Industri, 12(12), 301-309. 